\title{
The Effects of Radiotherapy on the Quality of Life in Localized Prostate Cancer Patients
}

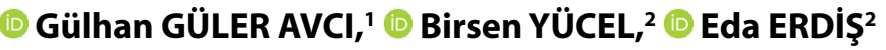 \\ 'Department of Radiation Oncology, University of Gaziosmanpaşa Faculty of Medicine, Tokat-Turkey \\ ${ }^{2}$ Department of Radiation Oncology, University of Cumhuriyet Faculty of Medicine, Sivas-Turkey
}

\begin{abstract}
OBJECTIVE
The present study aims to investigate the radiation-related toxicity and its effects on the quality of life in patients with prostate cancer who received definitive or adjuvant radiotherapy (RT).

\section{METHODS}

Eighty-seven localized prostate cancer patients who underwent RT between January 2011 and June 2016 were enrolled. Each patient filled the EORTC QLQC30 and QLQ-PR25 at four different times (starting and ending at RT, one and six months after RT). EORTC QLQ-C30 questionnaire consists of global health status, five functional (physical, role, cognitive, emotional, social) and nine symptom scales (fatigue nausea/vomiting, pain, dyspnea, insomnia, appetite loss, constipation, diarrhea and financial difficulties). EORTC QLQ-PR25 consists of two functional (sexual activity and sexual functioning) and four symptom scales (urinary, bowel, hormonal treatment-related, incontinence aid).
\end{abstract}

\section{RESULTS}

According to the EORTC QLQ-C30 questionnaire, global health status score ( $\mathrm{p}=0.007)$, emotional score $(\mathrm{p}=0.016)$, fatigue $(\mathrm{p}=0.004)$ and diarrhea score $(\mathrm{p}=0.003)$; according to EORTC QLQPR25 questionnaire, urinary score $(\mathrm{p}=0.024)$ were significantly poorer at the end of RT. When patients' quality of life questionnaires were compared concerning treatment type (definitive vs. adjuvant RT), RT technique (3D CRT vs. IMRT) and RT field (prostate/prostate+seminal vesicle vs. prostate+seminal vesicle+pelvic lymph node); EORTC QLQ C-30 and EORTC QLQ PR-25 functional and symptom scales were not different between groups.

\section{CONCLUSION}

The RT approach in prostate cancer produced temporary impairment in some scores of QLQ, but all these scores showed improvement from the first month after RT.

Keywords: Prostate cancer; quality of life; radiotherapy.

Copyright $\odot$ 2020, Turkish Society for Radiation Oncology

\section{Introduction}

Prostate cancer is a quite common type of cancer in men and 1.6 million new cases are reported each year. [1] Prostate cancer is one of the tumors that can be cured, especially when diagnosed at an early stage. Different treatments may be preferred depending on the cancer growth rate, spreading status, overall health status of the patient and the efficacy of the treatment to be performed, as well as possible side effects in the
Received: February 13, 2020

Accepted: February 14, 2020

Online: April 09, 2020

Accessible online at:

www.onkder.org

OPEN ACCESS This work is licensed under a Creative Commons

Attribution-NonCommercial 4.0 International License.
Dr. Gülhan GÜLER AVCI

Gaziosmanpaşa Üniversitesi Tıp Fakültesi,

Radyasyon Onkolojisi Anabilim Dalı,

Tokat-Turkey

E-mail: drgulhanguler@hotmail.com 
treatment of prostate cancer. While active monitoring is also an option of treatment in patients with lowrisk prostate cancer, in moderate or high-risk groups, surgery or radiotherapy (RT) with or without hormonotherapy constitutes radical treatment. The superiority of surgery or radiotherapy for survival has not been shown in local treatment.[2-4]

There are many studies showing that increased radiation doses significantly improved the rates of progression-free survival.[5-7] However, higher radiation doses increase acute and late adverse effects. Recently, the use of Intensity Modulated Radiotherapy (IMRT) somewhat reduced adverse effects compared to conventional radiotherapy.[8,9] However, organs at risk, such as bladder, rectum which are in the irradiation area, cannot be entirely protected from radiation. Thus, the quality of life of patients may alter due to the occurrence of radiation-related adverse effects. $[9,10]$

After the diagnosis, patients should deal with many problems, including the disease itself and the adverse effects related to the treatments. For diseases with alternative treatment options, the effects of therapies on quality of life (QoL) are important in choosing the treatment type. For this aim, the European Organization for Research and Treatment of Cancer (EORTC) has developed general and disease-specific QoL questionnaires to be used for cancer patients. EORTC QLQ-C30 is a questionnaire developed by EORTC that generally assesses the health-related QoL for cancer patients.[11] However, this questionnaire does not include issues specific to prostate cancer. Therefore, to specifically evaluate QoL of prostate cancer patients, EORTC has evolved a complementary module, QLQPR25.[12] Both questionnaires are reliable and commonly used in research all over the world.[13]

The present study aims to investigate the impacts of RT-related toxicity and its effects on the quality of life, using EORTC QLQ-C30 and QLQ-PR25 questionnaires in patients who received definitive or adjuvant RT for prostate cancer.

\section{Materials and Methods}

The Departmental Ethics Committee of Cumhuriyet University's Faculty of Medicine on non-invasive clinical research approved this trial in accordance with the Declaration of Helsinki with the decision no 2017$11 / 21$, on 8 November 2017. Eighty-seven localized prostate cancer patients who underwent RT in our department between January 2011 and June 2016 were enrolled. A consent form was obtained from all pa- tients who participated in this study. Prostate cancer patients who received curative or adjuvant RT were considered eligible.

Radiotherapy-induced side effects were assessed according to the Radiotherapy Oncology Group (RTOG) criteria.[14]

\section{Quality of Life Scale}

Each patient filled the EORTC QLQ-C30 and QLQPR25 at four different times: the start of RT (T1); the end of RT (T2); one month after completion of RT (T3); six months after completion of RT (T4).

Quality of life was judged using the EORTC QLQ-C30 version 3.0, a 30-item questionnaire. EORTC QLQ-C30 questionnaire consists of global health status, five functional (physical, role, cognitive, emotional, social) and nine symptom scales (fatigue nausea/vomiting, pain, dyspnea, insomnia, appetite loss, constipation, diarrhea and financial difficulties). [11] Cancer-specific QoL was evaluated utilising the EORTC QLQ-PR25 version 3.0, a 25-item questionnaire. EORTC QLQ-PR25 consists of two functional (sexual activity and sexual functioning) and four symptom scales (urinary, bowel, hormonal treatmentrelated, incontinence aid).[13] Patients' responses were assessed using the EORTC QLQ-C30 and QLQ-PR25 scoring manual. Scores as the symptom constituents were linearly turned into a scale of 0 to 100 . A high score as a functional scale indicated a comparatively high level of functioning, while a high score as a symptom scale demonstrated severe symptoms or financial influences.[15]

Radiotherapy was conducted utilising a linear accelerator device (Varian Clinac DHX, Varian Medical Systems, Inc., Palo Alto, CA, USA) and TomoTherapy (Accuray). Three-dimensional conformal RT planning was carried out using ECLIPS (Varian Medical Systems, Inc., Palo Alto, CA, USA). IMRT planning was done using Tomotherapy Planning Workstation (TomoTherapy Inc., Madison, WI). Of the 87 patients, sixty-two patients $(71 \%)$ were treated on the linear accelerator device, and twenty-five patients (29\%) were treated on the TomoTherapy. Doses of RT ranged from 66 to 80 Gy.

\section{Statistical Analysis}

SPSS version 23 was employed in the calculation of statistical data. Medians and frequencies were computed for patient demographics. Questionnaire scores were matched across the four times using the repeated-measures analysis of variance (ANOVA) and Freidman test 
(when distribution was not normal). A $\mathrm{p} \leq 0.05$ was regarded as statistically significant.

\section{Results}

Eighty-seven patients who underwent definitive and adjuvant RT were included in this study. Their median age was 67 years (range 49-78 years). There were comorbid diseases in 55 of the patients (63\%), 31 of these patients (56\%) had hypertension, 26 (47\%) had heart disease, and $18(33 \%)$ had diabetes mellitus. Secondary primary malignancy was also present in four (5\%) patients.

When the risk of disease was examined, 12 patients (14\%) had low-risk disease, 18 patients $(21 \%)$ had a moderate-risk disease and 57 patients $(65 \%)$ had highrisk disease.

Sixty-three patients $(72 \%)$ were treated with definitive RT and 24 patients (28\%) received adjuvant RT. Sixty of the patients (69\%) also received hormonotherapy treatment $(\mathrm{GnRH}$ analogue as leuprolide acetate $11.25 \mathrm{mg}$, and goserelin acetate $10.8 \mathrm{mg}$ was used for three months in moderate-risk patients, and two years

Table 1 Patient characteristics and treatment

\begin{tabular}{lcc} 
Characteristic & No of patients & $\%$ \\
\hline Comorbidity & 55 & 63 \\
Diabetes mellitus & 18 & 21 \\
Hypertension & 31 & 36 \\
Heart disease & 26 & 30 \\
Risk classification & 12 & \\
Low & 18 & 14 \\
Moderate & 57 & 21 \\
High & No of patients & $\%$ \\
Treatment & & 65 \\
\hline
\end{tabular}

Treatment

Definitive RT $\quad 63 \quad 72$

Adjuvant RT

24

28

Hormonotherapy

60

69

RT dose (median)

Definitive RT $76(66-80) \mathrm{Gy}$

Adjuvant RT 66 (66-72) Gy

RT technique

$\begin{array}{lll}3 \mathrm{D} C \mathrm{CRT}^{*} & 62 & 71\end{array}$

$\begin{array}{lll}\text { IMRT* }^{*} & 25 & 29\end{array}$

RT field

$\begin{array}{lll}\text { Prostate } & 12 & 14\end{array}$

Prostate+seminal vesicle $\quad 57 \quad 65$

Prostate+seminal vesicle+pelvic LN* $18 \quad 21$

*3D CRT: 3-dimensional radiotherapy, *IMRT: Intensity-modulated radiotherapy, ${ }^{*}$ LN: Lymph nodes in high-risk patients). There was a surgical margin positivity in 18 patients (75\%) who received adjuvant radiotherapy. In addition, 17 patients (71\%) with adjuvant RT had extracapsular invasion and 11 patients (46\%) had seminal vesicle invasion. Median radiation dose was 66 Gy (range 66-72 Gy) in patients treated with adjuvant $\mathrm{RT}$, whereas the median radiation dose was $76 \mathrm{~Gy}$ (range 66-80 Gy) in patients who underwent definitive RT. Radiotherapy fields were prostate in 12 patients (14\%), prostate+seminal vesicle in 57 patients $(65 \%)$, and prostate+seminal vesicle+pelvic lymph nodes in 18 patients (21\%). Patient characteristics and treatment details were given in Table 1.

When radiation-induced acute and late toxicities were examined, grade 3-4 lower gastrointestinal acute toxicity was observed in only one patient $(1 \%)$, grade 3-4 genitourinary acute toxicity was observed in two patients (2\%). Grade 3-4 late adverse effects were not observed. Radiotherapy-induced acute and late toxicities of scored according to RTOG were shown in Table 2. In addition, 56 of the patients (64\%) had erectile dys-

Table 2 Radiotherapy-induced early and late toxicities of scored according to RTOG

\begin{tabular}{|c|c|c|}
\hline Early toxicities & No of patients & $\%$ \\
\hline \multicolumn{3}{|l|}{ Lower GIS* tract } \\
\hline Grade 0 & 46 & 53 \\
\hline Grade 1-2 & 40 & 46 \\
\hline Grade 3-4 & 1 & 1 \\
\hline \multicolumn{3}{|l|}{ Genitourinary tract } \\
\hline Grade 0 & 15 & 17 \\
\hline Grade 1-2 & 70 & 81 \\
\hline Grade 3-4 & 2 & 2 \\
\hline \multicolumn{3}{|l|}{ Hematologic } \\
\hline$W_{B C}^{*}$ grade $1-2$ & 3 & 3 \\
\hline Platelet grade 1-2 & 2 & 2 \\
\hline Neutrophil grade 1-2 & 1 & 1 \\
\hline Hemoglobin grade 1-2 & 3 & 4 \\
\hline Hematocrit grade 1-2 & 2 & 2 \\
\hline Late toxicities & No of patients & $\%$ \\
\hline \multicolumn{3}{|l|}{ Bowel } \\
\hline Grade 0 & 80 & 92 \\
\hline Grade 1-2 & 7 & 8 \\
\hline \multicolumn{3}{|l|}{ Bladder } \\
\hline Grade 0 & 57 & 65 \\
\hline Grade 1-2 & 30 & 35 \\
\hline Erectile dysfunction & 56 & 64 \\
\hline Loss of libido & 54 & 62 \\
\hline Urinary incontinence & 21 & 24 \\
\hline
\end{tabular}

${ }^{*}$ GIS: Gastrointestinal; *WBC: White Blood Cell 
function, 54 of patients (62\%) had a loss of libido, and 21 of patients (24\%) had urinary incontinence.

Table 3 shows the results of the mean and standard deviation of EORTC QLQ-C30 measurements at the four-time points. EORTC QLQ-C30 questionnaire response ratios were $100 \%(\mathrm{n}=87)$ at $\mathrm{T} 1,100 \%(\mathrm{n}=87)$ at $\mathrm{T} 2,72 \%(\mathrm{n}=63)$ at $\mathrm{T} 3$, and $68 \%(\mathrm{n}=59)$ at T4. According to the EORTC QLQ-C30 questionnaire, the results of global health status score, emotional score in functional scale, fatigue and diarrhea score in symptoms scale were statistically significant.

Table 4 summarizes the EORTC QLQ-PR25 QOL results at the four-time points. EORTC QLQ_PR25 questionnaire response rates were $44 \%(\mathrm{n}=38)$ at $\mathrm{T} 1$, $38 \%(\mathrm{n}=33)$ at T2, 28\% $(\mathrm{n}=24)$ at T3, and $16 \%(\mathrm{n}=14)$ at T4. According to the EORTC QLQ-PR25 questionnaire, the result of the only urinary score in symptoms scale was statistically significant.

Figure 1 shows the graphics of the statistical significance results in the EORTC QLQ-C30 and QLQ-PR25 questionnaires.

When patients' QLQ were compared concerning treatment type (definitive RT vs. adjuvant RT), RT technique (3D conformal radiotherapy vs. IMRT) and RT field (prostate/prostate+seminal vesicle vs. prostate+seminal vesicle+pelvic lymph node); EORTC

Table 3 The EORTC QLQ-C30 QOL results at the four-time points

\begin{tabular}{|c|c|c|c|c|c|c|}
\hline $\begin{array}{l}\text { EORTC QLQ-C30 } \\
\text { Component }\end{array}$ & $\begin{array}{l}\text { Item } \\
\text { No./s }\end{array}$ & $\begin{array}{c}T_{1} \\
(n=87)\end{array}$ & $\begin{array}{c}T_{2} \\
(n=87)\end{array}$ & $\begin{array}{c}T_{3} \\
(n=63)\end{array}$ & $\begin{array}{c}T_{4} \\
(n=59)\end{array}$ & $\mathbf{p}$ \\
\hline Global health status & $29-30$ & $77 \pm 13$ & $72 \pm 26$ & $73 \pm 25$ & $83 \pm 25$ & 0.007 \\
\hline \multicolumn{7}{|l|}{ Functional scale } \\
\hline Physical & $1-5$ & $79 \pm 18$ & $79 \pm 24$ & $80 \pm 24$ & $85 \pm 27$ & 0.135 \\
\hline Role & 6,7 & $80 \pm 24$ & $77 \pm 27$ & $79 \pm 28$ & $86 \pm 29$ & 0.057 \\
\hline Emotional & $21-24$ & $83 \pm 21$ & $82 \pm 20$ & $79 \pm 23$ & $91 \pm 16$ & 0.016 \\
\hline Cognitive & 20,25 & $83 \pm 14$ & $86 \pm 17$ & $86 \pm 17$ & $85 \pm 16$ & 0.082 \\
\hline Social & 26,27 & $85 \pm 25$ & $86 \pm 17$ & $90 \pm 18$ & $88 \pm 19$ & 0.833 \\
\hline \multicolumn{7}{|l|}{ Symptoms scale } \\
\hline Fatigue & $10,12,18$ & $16 \pm 15$ & $26 \pm 23$ & $20 \pm 21$ & $16 \pm 23$ & 0.004 \\
\hline Nausea/vomiting & 14,15 & $2 \pm 7$ & $6 \pm 17$ & $5 \pm 11$ & $2 \pm 2$ & 0.226 \\
\hline Pain & 9,19 & $8 \pm 9$ & $19 \pm 22$ & $13 \pm 22$ & $12 \pm 25$ & 0.069 \\
\hline Dyspnea & 8 & $11 \pm 21$ & $18 \pm 29$ & $14 \pm 24$ & $14 \pm 20$ & 0.438 \\
\hline Insomnia & 11 & $8 \pm 17$ & $20 \pm 31$ & $21 \pm 28$ & $13 \pm 26$ & 0.068 \\
\hline Appetite loss & 13 & $6 \pm 18$ & $14 \pm 22$ & $11 \pm 22$ & $8 \pm 19$ & 0.142 \\
\hline Constipation & 16 & $7 \pm 18$ & $15 \pm 24$ & $10 \pm 23$ & $4 \pm 11$ & 0.153 \\
\hline Diarrhea & 17 & $1 \pm 6$ & $17 \pm 30$ & $10 \pm 23$ & $3 \pm 10$ & 0.003 \\
\hline Financial difficulties & 28 & $10 \pm 20$ & $13 \pm 18$ & $9 \pm 19$ & $14 \pm 25$ & 0.644 \\
\hline
\end{tabular}

$\mathrm{T}_{1}:$ Start of radiotherapy; $\mathrm{T}_{2}$ : End of radiotherapy; $\mathrm{T}_{3}: 1$ month after completion of radiotherapy; $\mathrm{T}_{4}: 6$ months after completion of radiotherapy

Table 4 The EORTC QLQ-PR25 QOL results at the four-time points

\begin{tabular}{|c|c|c|c|c|c|c|}
\hline $\begin{array}{l}\text { EORTC QLQ-PR25 } \\
\text { Functional scale }\end{array}$ & $\begin{array}{l}\text { Item } \\
\text { No./s }\end{array}$ & $\begin{array}{c}T 1 \\
(n=38)\end{array}$ & $\begin{array}{c}\text { T2 } \\
(n=33)\end{array}$ & $\begin{array}{c}\text { T3 } \\
(n=24)\end{array}$ & $\begin{array}{c}\text { T4 } \\
(n=14)\end{array}$ & $\mathbf{p}$ \\
\hline Sexual activity & 20,21 & $77 \pm 37$ & $93 \pm 15$ & $83 \pm 29$ & $80 \pm 30$ & 0.801 \\
\hline Sexual functioning* & $22-25$ & - & - & - & - & - \\
\hline Symptoms scale & No./s & $(n=54)$ & $(n=54)$ & $(n=32)$ & $(n=24)$ & $\mathbf{p}$ \\
\hline Urinary & $1-7,9$ & $17 \pm 12$ & $34 \pm 20$ & $19 \pm 13$ & $11 \pm 12$ & 0.024 \\
\hline Bowel & $10-13$ & $0.7 \pm 3$ & $6 \pm 11$ & $2 \pm 3$ & $0.7 \pm 3$ & 0.216 \\
\hline Hormonal treatment-related & $14-19$ & $15 \pm 8$ & $12 \pm 11$ & $12 \pm 10$ & $10 \pm 10$ & 0.270 \\
\hline Incontinence aid & 8 & $6 \pm 20$ & $9 \pm 20$ & $30 \pm 11$ & $0 \pm 0$ & 0.488 \\
\hline
\end{tabular}

$\mathrm{T}_{1}$ : Start of radiotherapy; $\mathrm{T}_{2}$ : End of radiotherapy; $\mathrm{T}_{3}: 1$ month after completion of radiotherapy; $\mathrm{T}_{4}: 6$ months after completion of radiotherapy; ${ }^{*}$ : The number of cases responding to this question was insufficient 

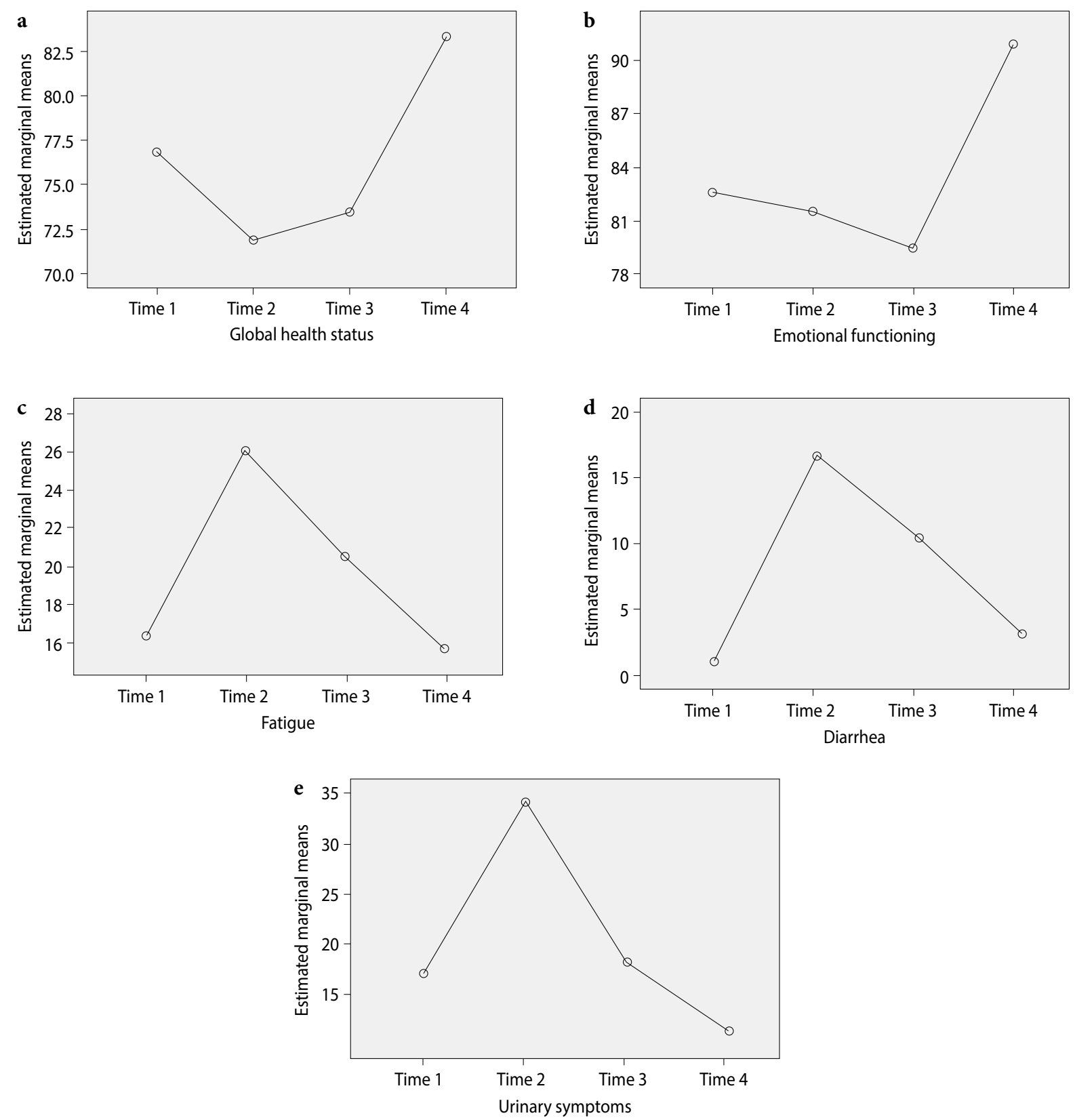

Fig. 1. The graphics of the statistical significance results in both questionnaire.

QLQ C-30 and EORTC QLQ PR-25 functional and symptom scales were not different between groups $(\mathrm{p}>0.05)$.

\section{Discussion}

Prostate cancer constitutes a patient group with longer life expectancy compared to other cancer types. The effects of treatments on the quality of life are very essen- tial, especially for patients with early-stage, slow-growing tumors that are expected to live longer. In patients without metastatic disease, radical prostatectomy and RT constitute local treatments. In the present study, we investigated the effects of RT-related toxicity and its effects on the quality of life in patients with prostate cancer received definitive or adjuvant RT. Acute, grade 3-4 lower gastrointestinal toxicity was observed in only one patient (1\%), acute grade 3-4 genitourinary toxic- 
ity was observed in two patients (2\%). Fifty-six of the patients (64\%) had erectile dysfunction, 54 of patients (62\%) had a loss of libido and 21 of patients (24\%) had urinary incontinence. In the EORTC QLQ-C30 questionnaire, global health status, emotional score in functioning scale, fatigue and diarrhea scores in symptoms scale were negatively affected during RT. However, all these scores showed improvement from the first month after RT. In the EORTC QLQ-PR25 questionnaire, only the urinary score was negatively affected by RT, which also improved as the others.

Marchand et al.[16] examined radiotherapy-induced toxicity and its effect on QoL of 55 patients receiving RT for localized prostate cancer. External RT was applied with IMRT technique in doses of $76 \mathrm{~Gy}$. EORTC QLQ C30 and QLQ PR25 questionnaires, which were used to assess QoL, were administered on patients before RT (baseline) and 2, 6 and 18 months after RT. The results of the study showed acute grade 1 and grade 2 urinary toxicity was $56.4 \%$ and $38.2 \%$, respectively, while acute grade 1 and grade 2 bowel toxicity were $36.4 \%$ and $12.7 \%$, respectively. Significant improvements were reported in the bowel and urinary toxicity six months after RT. Urethral stenosis was observed in a patient as an acute grade 3 genitourinary adverse effect. In addition, grade 1 and grade 2 sexual impotence were reported in $33 \%$ and $12 \%$ of patients, respectively, in the 18th month after RT.[16] In another similar study, Goineau et al.[17] studied the effects of high dose (76 Gy) RT on acute and late toxicity and on QoL in 38 patients with localized prostate cancer. They utilised the Common Terminology Criteria for Adverse Events questionnaire (version 3.0) to assess toxicity and EORTC QLQ-C30 and QLQ-PR25 questionnaires to assess QoL. Questionnaires were applied before and 2, 6, 18 and 54 months after RT. Acute urinary and gastrointestinal grade 1 toxicities were $36.8 \%$ and $23.7 \%$, grade 2 toxicities were $5.3 \%$ and $5.3 \%$, and grade 3 toxicities were $2.6 \%$ and $0 \%$, respectively.[17] In the same study, grade 1 urinary and gastrointestinal toxicities in 18 th month were $23.7 \%$ and $10.3 \%$, grade 2 were $26.3 \%$ and $13.2 \%$ and grade 3 were $0 \%$ and $2.6 \%$, respectively, while in the $54^{\text {th }}$-month grade 1 toxicities were $34.2 \%$ and $23.7 \%$, grade 2 were $5.3 \%$ and $5.8 \%$ and grade 3 were $5.3 \%$ and $0 \%$, respectively. In the present study, relatively higher side effects due to radiotherapy were observed compared to those two studies. $[16,17]$ However, the patients undergoing both conformal RT and IMRT were included in our study. Acute grade 1-2 gastrointestinal toxicity was observed in $46 \%$ of patients and grade $3-4$ toxicity in $1 \%$ of pa- tients, while acute grade 1-2 urinary toxicity was observed in $81 \%$ and grade $3-4$ toxicity in $2 \%$ of patients in the present study. As late toxicity, urinary and gastrointestinal grade 1-2 toxicities were seen in $8 \%$ and $35 \%$ of patients, respectively, whereas none of the patients had grade 3-4 toxicities.

In the present study, other adverse effects, observed in late periods, were erectile dysfunction (64\%), loss of libido (62\%) and urinary incontinence (24\%). In our patients, the rate of sexual impotence was also high with the addition of hormone therapy (69\%) and adjuvant RT (28\%), which cause loss of libido. In addition, urinary continence was the most commonly encountered adverse effect in patients receiving adjuvant RT. In their studies examining the side effects of RT after 2-3 years, Little et al.[18] determined that $83 \%$ of patients had an erectile function before RT, they showed that this rate decreased to $49 \%$ two years after RT and to $41 \%$ after three years. A urinary incontinence rate of $36 \%$ was also reported in the same study.

Marchand et al.[16] reported significant impairments in some scores of QoL questionnaires after RT applied to patients with localized prostate cancer at $76 \mathrm{~Gy}$ doses. In the second month after RT, deteriorations in QoL were seen in fatigue and dyspnea scores of symptoms scale, in emotional, social, cognitive, physical scores of the functional scale of EORTC QLQ C-30 questionnaire, and in urinary symptom scores of EORTC QLQ PR-25 questionnaire. In the sixth month after RT, there were improvements in emotional, social, cognitive, physical, fatigue scores, and in 18th month, only treatment-related symptoms score was higher compared to baseline. [16] In the present study, global health status, emotional scores of functional scale, fatigue and diarrhea scores of symptom scale in the EORTC QLQ C-30 questionnaire were negatively affected at the end of RT. These scores, which had been impaired as a result of early adverse effects of RT, returned completely to baseline levels in the first and sixth months after RT. In the EORTC QLQ PR-25 questionnaire, only urinary score was negatively affected, which returned to normal in the first and sixth months after RT, similar to other scores. Since enough number of patients did not answer the questions related to sexual function in the questionnaire, the sexual functioning score was not assessed. Although some studies reported permanent impairments in QoL associated with sexual activity after RT,[18-22] there was no change in sexual activity score compared to before RT in the present study.

Lips et al.[23] compared 88 patients with localized prostate cancer who received 70 Gy doses via 3D- 
Conformal radiotherapy technique and 92 patients who received 76 Gy doses using the IMRT technique concerning their quality of life. RAND-36, EORTC QLQ C-30 and QLQ PR25 questionnaires were used to evaluate QoL of patients before RT (baseline), one and six months after RT. No grade 3-4 bowel and urinary toxicities were reported in both treatment groups. Only one patient had grade 3 urinary infection in the high dose treatment group. Based on the EORTC questionnaire, the patients who had 70 Gy RT had a temporary deterioration in pain and urinary symptom scores of symptoms scale. In higher doses, i.e. in the group of IMRT, QoL did not alter significantly compared to conformal RT. Despite higher dose application to patients receiving IMRT, impairment of QoL due to bowel functioning was reported to be lower compared to patients receiving conformal RT.[23] In another similar study from Japan, 110 patients with prostate cancer who underwent conformal RT (median $70 \mathrm{~Gy}$ ) and 30 patients who underwent IMRT (median $76 \mathrm{~Gy}$ ) were compared in terms of their quality of life. [19] As a difference, the authors assessed QoL using the Medical Outcomes Study 36-Item Short Form (SF-36) and prostate-specific QoL using the University of California, Los Angeles, Prostate Cancer Index (UCLA PCI). There was no difference between the two groups for urinary symptoms, but the Japanese study demonstrated that bowel functions and sexual activity of the patients were significant impaired in the third and sixth months after RT in the conformal radiation group.[19] In the present study, RT was applied to $71 \%$ of patients with 3D-conformal RT technique. Similar to the above-mentioned studies,[19,23] there were no differences in the scores of the QoL questionnaires between the groups of patients receiving conformal radiotherapy and IMRT. Also, no significant difference was found between patients who had undergone definitive and adjuvant RT concerning QoL.

Some researchers have shown that pelvic lymph node irradiation in high-risk patient groups negatively affects symptom-related QoL, especially diarrhea because more intestine enters the RT field.[24,25] Majewski et al.[24] studied the effects of RT on QoL of 180 prostate cancer patients using EORTC questionnaires. A total of $76 \mathrm{~Gy}$ was implemented to $85 \%$ of the patients using the IMRT technique and the remaining 15\% to the patients using the conformal technique. Pelvic lymph node irradiation (44 Gy) was performed for a high-risk patient group (41\%). Especially, in patient group receiving pelvic lymph node irradiation, significant deteriorations in symptom-related QoL (urinary symptoms and diarrhea) were observed.[24] Unlike the above-mentioned studies, no significant difference was found in any of the QoL questionnaire scores of patients who were irradiated to the pelvic lymph nodes compared to patients without pelvic lymph node irradiation in our study.

\section{Conclusion}

The RT approach in prostate cancer caused temporary impairment in some scores of QLQ, but all these scores showed improvement from the first month after RT.

Peer-review: Externally peer-reviewed.

Conflict of Interest: No conflict of interest.

Ethics Committee Approval: The Departmental Ethics Committee of Cumhuriyet University's Faculty of Medicine on non-invasive clinical research approved this trial in accordance with the Declaration of Helsinki with the decision no 2017-11/21, on 8 November 2017.

Financial Support: None declared.

Authorship contributions: Concept - B.Y.; Design - B.Y.; Supervision - None; Funding - None; Materials - E.E.; Data collection and/or processing - E.E.; Data analysis and/or interpretation - B.Y.; Literature search - G.G.A.; Writing G.G.A.; Critical review - G.G.A., B.Y.

\section{References}

1. Crawford ED. Epidemiology of prostate cancer. Urology 2003;62(6 Suppl 1):3-12.

2. Wilt TJ, MacDonald R, Rutks I, Shamliyan TA, Taylor BC, Kane RL. Systematic review: comparative effectiveness and harms of treatments for clinically localized prostate cancer [published correction appears in Ann Intern Med. 2008 Jun 3;148(11):888]. Ann Intern Med 2008;148(6):435-48.

3. Bolla M, Collette L, Blank L, Warde P, Dubois JB, Mirimanoff RO, et al. Long-term results with immediate androgen suppression and external irradiation in patients with locally advanced prostate cancer (an EORTC study): a phase III randomised trial. Lancet 2002;360(9327):103-6.

4. Heidenreich A, Aus G, Bolla M, Joniau S, Matveev VB, Schmid HP, Zattoni F; European Association of Urology. EAU guidelines on prostate cancer. Eur Urol 2008;53(1):68-80.

5. Peeters ST, Heemsbergen WD, Koper PC, van Putten WL, Slot A, Dielwart MF, et al. Dose-response in radiotherapy for localized prostate cancer: results of the Dutch multicenter randomized phase III trial compar- 
ing 68 Gy of radiotherapy with 78 Gy. J Clin Oncol 2006;24(13):1990-6.

6. Zietman AL, DeSilvio ML, Slater JD, Rossi CJ Jr, Miller DW, Adams JA, et al. Comparison of conventionaldose vs high-dose conformal radiation therapy in clinically localized adenocarcinoma of the prostate: a randomized controlled trial. JAMA 2005;294(10):1233-9.

7. Pollack A, Zagars GK, Starkschall G, Antolak JA, Lee JJ, Huang E, et al. Prostate cancer radiation dose response: results of the M. D. Anderson phase III randomized trial. Int J Radiat Oncol Biol Phys 2002;53(5):1097-105.

8. Ling CC, Burman C, Chui CS, Kutcher GJ, Leibel SA, LoSasso $\mathrm{T}$, et al. Conformal radiation treatment of prostate cancer using inversely-planned intensitymodulated photon beams produced with dynamic multileaf collimation. Int J Radiat Oncol Biol Phys 1996;35(4):721-30.

9. Chauvet I, Gaboriaud G, Pontvert D, Zefkili S, Giraud $\mathrm{P}$, Rosenwald JC, et al. Constraints and dosage for prostate cancer patients treated with conformal radiotherapy and intensity modulated radiation therapy. Cancer Radiother 2004;8(6):337-51.

10.Zelefsky MJ, Fuks Z, Hunt M, Yamada Y, Marion C, Ling CC, et al. High-dose intensity modulated radiation therapy for prostate cancer: early toxicity and biochemical outcome in 772 patients. Int J Radiat Oncol Biol Phys 2002;53(5):1111-6.

11. Fayers P, Aaronson NK, Bjordal K, Groenvold M, Curran D, Bottomley A. EORTC QLO-C30 scoring manual. 3rd ed. Brussels: European Organisation for Research and Tretament Cancer Data Center; 2001.

12. Borghede G, Sullivan M. Measurement of quality of life in localized prostatic cancer patients treated with radiotherapy. Development of a prostate cancer-specific module supplementing the EORTC QLQ-C30. Qual Life Res 1996;5(2):212-22.

13. van Andel G, Bottomley A, Fosså SD, Efficace F, Coens C, Guerif S, et al. An international field study of the EORTC QLQ-PR25: a questionnaire for assessing the health-related quality of life of patients with prostate cancer. Eur J Cancer 2008;44(16):2418-24.

14. Cox JD, Stetz J, Pajak TF. Toxicity criteria of the Radiation Therapy Oncology Group (RTOG) and the European Organization for Research and Treatment of Cancer (EORTC). Int J Radiat Oncol Biol Phys 1995;31(5):1341-6.

15. Aaronson NK, Ahmedzai S, Bergman B, Bullinger M, Cull A, Duez NJ, et al. The European Organization for Research and Treatment of Cancer QLQ-C30: a quality-of-life instrument for use in international clinical trials in oncology. J Natl Cancer Inst 1993;85(5):36576.
16. Marchand V, Bourdin S, Charbonnel C, Rio E, Munos C, Campion L, et al. No impairment of quality of life 18 months after high-dose intensity-modulated radiotherapy for localized prostate cancer: a prospective study. Int J Radiat Oncol Biol Phys 2010;77(4):1053-9.

17. Goineau A, Marchand V, Rigaud J, Bourdin S, Rio E, Campion L, et al. Prospective evaluation of quality of life 54 months after high-dose intensity-modulated radiotherapy for localized prostate cancer. Radiat Oncol 2013;8:53.

18. Little DJ, Kuban DA, Levy LB, Zagars GK, Pollack A. Quality-of-life questionnaire results 2 and 3 years after radiotherapy for prostate cancer in a randomized dose-escalation study. Urology 2003;62(4):707-13.

19. Namiki S, Ishidoya S, Tochigi T, Kawamura S, Kuwahara $M$, Terai A, et al. Health-related quality of life after intensity modulated radiation therapy for localized prostate cancer: comparison with conventional and conformal radiotherapy. Jpn J Clin Oncol 2006;36(4):224-30.

20. Wahlgren T, Brandberg Y, Häggarth L, Hellström M, Nilsson S. Health-related quality of life in men after treatment of localized prostate cancer with external beam radiotherapy combined with (192)ir brachytherapy: a prospective study of 93 cases using the EORTC questionnaires QLQ-C30 and QLQ-PR25. Int J Radiat Oncol Biol Phys 2004;60(1):51-9.

21. Korfage IJ, Essink-Bot ML, Borsboom GJ, Madalinska JB, Kirkels WJ, Habbema JD, et al. Five-year follow-up of health-related quality of life after primary treatment of localized prostate cancer. Int J Cancer 2005;116(2):291-6.

22. Yoshimura K, Arai Y, Ichioka K, Matsui Y, Ogura K, Terai A. A 3-y prospective study of health-related and disease-specific quality of life in patients with nonmetastatic prostate cancer treated with radical prostatectomy or external beam radiotherapy. Prostate Cancer Prostatic Dis 2004;7(2):144-51.

23. Lips I, Dehnad H, Kruger AB, van Moorselaar J, van der Heide U, Battermann J, et al. Health-related quality of life in patients with locally advanced prostate cancer after 76 Gy intensity-modulated radiotherapy vs. 70 Gy conformal radiotherapy in a prospective and longitudinal study. Int J Radiat Oncol Biol Phys 2007;69(3):656-61.

24. Majewski W, Tabor K, Prokop E, Kulik R. Quality of life in patients with prostate cancer treated with radical image-guided radiotherapy. Contemp Oncol (Pozn) 2014;18(4):285-9.

25. Pinkawa M, Piroth MD, Holy R, Fischedick K, Klotz J, Székely-Orbán D, et al. Quality of life after whole pelvic versus prostate-only external beam radiotherapy for prostate cancer: a matched-pair comparison. Int J Radiat Oncol Biol Phys 2011;81(1):23-8. 